\title{
A cooperação internacional descentralizada como estratégia para a proteção da sociobiodiversidade
}

\author{
Marcos Vinícius Ast de Almeida* \\ Mohammed Nadir** \\ Luiz Ernani Bonesso de Araújo***
}

\section{INTRODUÇÃO}

Talvez nada no mundo seja tão fortemente compartilhado por todos os seres, ou esteja implicado tão diretamente no futuro de toda a humanidade, do que a questão ambiental. Na condição de bem público global, as questões ambientais desafiam as fronteiras dos Estados Nacionais, e tendem a questionar a soberania nacional e outros parâmetros que permitem compreender um mundo social e politicamente dividido, uma vez que, invariavelmente, quando se trata do meio ambiente, a humanidade compartilha um destino comum inerente a sua própria existência e sobrevivência.

Apesar disso, as decisões políticas mais contundentes sobre o destino das pessoas e do planeta, em força e extensão, ainda permanecem alijadas à vontade dos Estados. Estes, por sua vez, ainda que tenham perdido o protagonismo - para o capital financeiro e as multinacionais - enquanto atores centrais das relações internacionais, continuam desempenhando um papel fundamental nesse

\footnotetext{
* Mestrando do Programa de Pós-Graduação em Direito (PPGD) da Universidade Federal de Santa Maria (UFSM), na linha de pesquisa "Direitos na sociedade em rede: atores, fatores e processos na mundialização". Graduado em Direito na Universidade Franciscana (UFN). Assessor da ProcuradoriaGeral de Justiça do Estado do Rio Grande do Sul. Pesquisador do NPPDI - Núcleo de Pesquisa e Práticas em Direito Internacional (CNPq/UFSM). E-mail: marcosviniciusast@yahoo.com.br.

** Mestrando do Programa de Pós-Graduação em Direito (PPGD) da Universidade Federal de Santa Maria (UFSM), na linha de pesquisa "Direitos na sociedade em rede: atores, fatores e processos na mundialização". Graduado em Direito na Universidade Franciscana (UFN). Assessor da ProcuradoriaGeral de Justiça do Estado do Rio Grande do Sul. Pesquisador do NPPDI - Núcleo de Pesquisa e Práticas em Direito Internacional (CNPq/UFSM). E-mail: marcosviniciusast@yahoo.com.br.

*** Doutor em Direito. Professor Titular aposentado da Universidade Federal de Santa Maria UFSM. Professor do Mestrado em Direito da Universidade de Passo Fundo - UPF.
} 
cenário, permanecendo os principais produtores do Direito e sujeitos do Direito Internacional.

Nesse contexto, competem com os Estados, os interesses de grandes corporações e atores privados que, em conjunto com aqueles, impulsionam o avanço da globalização e a expansão dos mercados de capitais, para os quais, muitas vezes, as questões ambientais são um empecilho ao desenvolvimento e crescimento econômico. Em decorrência disso, as normas de Direito Internacional relacionadas à proteção do meio ambiente perdem sua força e dão oportunidade à nefastas práticas econômicas e desenvolvimentistas dos Estados e dos mercados financeiros ao redor do mundo.

Por outro lado, em resposta ao descaso ou à exploração ambiental anuída por esses atores clássicos das relações internacionais, novos atores vêm emergindo e contribuindo fundamentalmente para a proteção do meio ambiente, disseminando práticas que fomentam, a desconfiança e o custo político dos Estados sobre as decisões que implicam no destino do planeta. Nesse passo, o propósito deste artigo é investigar a cooperação descentralizada como estratégia de governança global do meio ambiente e nomeadamente no que diz respeito à sociobiodiversidade. Para tanto, parte-se do pressuposto de que a globalização e a mundialização ${ }^{1}$ (HIRST, Paul; THOMPSON, Grahame, 1998; RENATO ORTIZ, 1994) provocaram significativas mudanças na arena das relações internacionais, retirando o protagonismo dos Estados em razão do surgimento de novos atores tão ou mais importantes, como os movimentos sociais, o setor privado, as organizações não governamentais etc.

O artigo é dividido em dois tópicos, sendo que no primeiro deles é enfrentado o papel da cooperação internacional para o desenvolvimento, e este como um exemplo que dificulta ou impede a proteção da sociobiodiversidade. No segundo tópico, por fim, é enfrentada a ideia de cooperação descentralizada e da luta social com a finalidade de alcançar uma justiça ambiental mais democrática.

\section{A COOPERAÇÃO INTERNACIONAL E A QUESTÃO DO DESENVOLVIMENTO}

A cooperação internacional pode ser tradicionalmente definida como a atuação conjunta de Estados e instituições multilaterais em busca da satisfação de objetivos comuns. Ou seja, os países e instituições somam esforços para superar ou enfrentar desafios conjuntos, buscando o desenvolvimento a partir da troca de experiências, de conhecimentos e de boas práticas (RIBEIRO, 2007, p. 432).

Especificamente em relação ao desenvolvimento, a cooperação internacional pode ser compreendida pelo conjunto de ações projetadas e executadas pelos Estados na busca de um progresso mais justo e equilibrado (SÁNCHEZ, 2002). Porém, em um contexto internacional tão desigual, nem 
sempre justiça e equilíbrio podem ser adjetivos utilizados para descrever essas práticas.

Considerando principalmente a ideia de que a cooperação nada mais é do que a soma de esforços, colaboração e auxílio supostamente mútuos, seria coerente pensar que nenhum país ou organização realizaria um acordo com o objetivo de prejudicar a si próprio. Se há um problema local que precisa ser solucionado, evidentemente que é melhor enfrentá-lo sozinho ao invés de firmar um acordo de cooperação que, no final das contas, poderá agravar esse ou outros problemas já enfrentados pelo país e por sua população.

Contudo, a lógica do direito e das relações internacionais nem sempre segue esse raciocínio aparentemente coerente, não raramente se mostrando perversa e motivo do adensamento das desigualdades e das assimetrias entre os Estados. Logo, algumas estratégias de cooperação têm se mostrado bastante ineficazes em responder a grandes problemas suportados pelas sociedades local e internacional, especialmente no que diz respeito às questões envolvendo o meio ambiente (ULLRICH; CARRION, 2012).

No contexto global, talvez nenhum outro bem seja tão fortemente compartilhado por todos os Estados e grupos sociais do que o meio ambiente, uma vez que todos os seres humanos estão inseridos em um mesmo planeta e invariavelmente compartilham um destino comum. Logo, as ações e interações que ocorrem nesse mesmo plano causam e/ou em algum momento causarão impactos em relação a todas as pessoas.

Consequentemente, a questão ambiental é capaz de "globalizar identidades, afinidades e interesses para além das categorias tradicionais como nações, raças ou hemisférios, e de generalizar preocupações como o direito humano ao bem-estar e a bens comuns" (CERQUEIRA, 1994, p. 02). Por esse motivo e devido ao seu profundo caráter compartilhado, a lógica seria a da soma de esforços entre os mais diversos atores, especialmente no contexto internacional, por meio do alinhamento de interesses na preservação do meio ambiente e da sociobiodiversidade.

Historicamente, porém, não é preciso nenhum olhar científico apurado para perceber que a questão ambiental tem colapsado, e que o meio ambiente e a sociobiodiversidade vêm sendo alvo de constantes e exponenciais degradações, em detrimento do interesse de diversos agentes, inclusive, e principalmente, dos próprios Estados. Basta referir que os grandes pasies emissores de dióxido de carbono são as maiores potências do mundo a saber China, Estados Unidos da América, Rússia, Índia e Japão. Nesse passo, ao longo das últimas décadas, tem-se percebido que as ações de cooperação entre os países têm sido meramente paliativas em relação à preservação do meio ambiente, resumindo-se a adoção de medidas cujo único resultado e a manutenção da lógica do sistema capitalista. Ou seja, contraditoriamente, as medidas compartilhadas entre os Estados sobre as questões ambientais têm visado, em maior ou menor grau, a assegurar a 
sobrevivência de um sistema de exploração de recursos incompatível com a preservação da sociobiodiversidade (LE PRESTRE, 2000, p. 160).

Nesse sentido, seguindo a lógica capitalista, as decisões que visam o crescimento econômico dos Estados parecem ter um peso político muito maior, e uma adesão muito mais significativa dos principais atores das relações internacionais. Em função disso, a necessidade de satisfação dos interesses do mercado, associada à ideia do desenvolvimento econômico, condiciona as demais decisões políticas dos Estados, mesmo que isso ocorra à custa da degradação de outros bens comuns essenciais à sobrevivência e bem-estar sociais. Assim, a política, e principalmente a política internacional, opera seletivamente, nem sempre de forma a preservar os interesses sociais e os bens comuns (SHIVA, 2001).

Essa seletividade e divergência acabam restringindo o cumprimento de determinados objetivos e acordos de cooperação, visto que o impacto das decisões econômicas é muito maior e por conseguinte tende a negligenciar outras questões fundamentais, como aquelas relacionadas ao meio ambiente. Com efeito, a cooperação internacional entre os Estados torna-se, nessa área, cada vez mais utópica, na contramão do avanço duma consciência mundial global sobre os problemas ambientais (SHIVA, 2001).

Outra questão que contribui fortemente para que a cooperação internacional ambiental se distancie cada vez mais dos seus ideais, é o fato de que a lógica da cooperação parte de um modelo do desenvolvimento que perpetua a relação verticalizada entre os países do Norte e Sul Globais. Ou seja, a globalização impôs um regime de concorrência econômica entre os Estados, de modo que as relações entre eles são desiguais e, por vezes, os Estados do Sul Global negligenciam questões locais essenciais em detrimento de acordos de cooperação que favorecem os interesses dos países desenvolvidos (ARAÚJO, 2011; TOURME-JOUANNET, 2013).

A ideia de desenvolvimento, por si só, já é uma ideia subjetiva, uma vez que se almeja partir de uma situação pior ou menos favorável, para outra situação melhor ou menos desfavorável. Ou seja, é evidente que há uma relação comparativa e dialética que envolve a ideia de progresso, compreendendo a definição de metas e objetivos. E isso necessariamente implica em dizer que existem Estados desenvolvidos, que supostamente já atingiram essas metas, e que existem Estados subdesenvolvidos ou em desenvolvimento. Não há como falar em desenvolvimento sem pensar sobre a ausência dele, e igualmente como e quem define os critérios do subdesenvolvimento. Ou seja, qual o ponto de partida do subdesenvolvimento e o ponto de chegada do desenvolvimento (TOURMEJOUANNET, 2013).

Deve dizer que essas questões, especialmente pensadas sobre o aspecto dos países e grupos que integram o Norte e o Sul Globais, estão diretamente relacionadas à exploração derivada dos períodos coloniais, através dos quais o desenvolvimento dos países do Norte foi alcançado em detrimento da exploração 
de recursos ambientais e humanos do Sul. Assim, o conceito do desenvolvimento ${ }^{2}$ partiu - e em determinado grau ainda parte - de um conjunto complexo de fatores utilizado para garantir o interesse dos Estados ricos e imperialistas em detrimento das colônias, sendo utilizada como estratégia para perpetuar um programa de colonização e dominação (TOURME-JOUANNET, 2013).

Nesse passo, o desenvolvimento foi antes de tudo uma preocupação de alguns Estados na manutenção dos seus interesses, em detrimento dos Estados mais pobres. E o desenvolvimento das colônias ou dos países do Sul era e permanece sendo medido pelo desenvolvimento dos países antes colonizadores e que hoje integram o Norte Global. Esse é o principal motivo pelo qual as excolônias passaram a ser concebidas como países subdesenvolvidos e, mais tarde, mais diplomaticamente, como países em desenvolvimento. Em suma, o desenvolvimento permaneceu sendo uma ideia continuada de dominação colonial (TOURME-JOUANNET, 2013).

Apesar disso, a busca pelo desenvolvimento tornou-se o fator chave para a reconstrução de um mundo pós-colonial, figurando um dos mais fortes padrões do direito internacional. Logo, a busca pelo progresso tornou-se o centro nevrálgico de ajuda e da cooperação entre os países, especialmente dos países desenvolvidos para os países em desenvolvimento, fomentando programas de ajuda assistencial e técnica para esses países (TOURME-JOUANNET, 2013).

A par das discussões sobre o conceito de desenvolvimento, as decisões políticase econômicas também ficam à mercêda mesquinhez e da espetacularização protagonizada pelos principais atores políticos dos Estados, como foi possível observar recentemente no imbróglio travado entre o Presidente Brasileiro, Jair Bolsonaro, e o Presidente Francês, Emmanuel Macron, sobre o alcance de recursos destinados à contenção de queimadas e à preservação da Floresta Amazônica. Ao sentir-se ofendido pelas palavras do Presidente da França, o Chefe do Poder Executivo Brasileiro chegou a afirmar que somente aceitaria o auxílio de outros Estados e instituições internacionais caso recebesse um pedido de desculpas de Macron (ESTADÃO, 2019).

Em meio às discussões adolescentes de ambos os Presidentes, ficou nítido que o ego ferido de Bolsonaro teve um peso muito mais forte nas decisões políticas tomadas por ele em relação ao caso, ao invés da possibilidade de obtenção de ajuda internacional para a solução do gravíssimo problema ambiental enfrentado pelo Brasil. Ou seja, o orgulho pessoal do Presidente revelou-se mais importante do que os interesses de Estado que ele deveria representar e defender, e que têm repercussões drásticas na vida de milhões de pessoas, especialmente no que diz respeito à preservação da sociobiodiversidade Amazônica (ESTADÃO, 2019).

É claro que aqui não se está a discutir quais os interesses escusos por detrás da oferta de ajuda internacional, e quais foram ou são as condições dessa ajuda no contexto da cooperação para a "preservação" da Floresta Amazônica. Afinal, como se disse anteriormente, nem sempre - ou quase nunca - a lógica das 
relações internacionais opera num sentido de solidariedade altruísta, sem que seja cobrada uma contraprestação em troca da "ajuda” recebida.

Contudo, os motivos das decisões políticas é que merecem destaque. A par dessa breve reflexão, o que se quer demonstrar é a fugacidade da política internacional, e de como a discussão sobre a resolução de problemas e a administração de bens globais fica à mercê de outras questões menos relevantes, senão insignificantes diante da dimensão dos problemas enfrentados ao redor do mundo, ou de questões de grande impacto negativo na administração e preservação de outros recursos tão ou mais importantes, como a questão ambiental e o avanço da globalização capitalista. No caso da ajuda internacional para a preservação da Amazônia, a recusa poderia ter sido fortemente embasada seja em razão da sua efetiva desnecessidade, seja em razão dos termos da cooperação. Porém, o embasamento não revelou qualquer interesse ou oposição de Estado, mas sim os embaraços pessoais envolvendo o Presidente do Brasil.

Por conseguinte, considerando o caráter dicotômico e contraditório do próprio desenvolvimento, e partindo-se desse mesmo esquema, também podem ser reconhecidos dois modelos conflitantes sobre a biodiversidade. Segundo Vandana Shiva:

O primeiro é mantido pelas comunidades locais, cuja sobrevivência e sustentabilidade estão ligadas ao uso e conservação da biodiversidade. O segundo é mantido pelos interesses comerciais, cujos lucros estão ligados à utilização da biodiversidade global como insumos de sistemas de produção globais, centralizados e homogêneos. (SHIVA, 2001, p. 146)

Consequentemente, é mais fácil identificar no segundo exemplo o lugar dos interesses dos Estados, reforçados pelo direito internacional e pelos esquemas e acordos da cooperação para o desenvolvimento. As respostas dadas por esses atores tradicionais aos problemas ambientais reflete a medida do afastamento do ser humano da natureza; e uma análise crítica desses esquemas permite até mesmo associar a cooperação internacional tradicional entre os Estados a partir do uso despreocupado dos recursos naturais, partindo da valorização de um conhecimento científico em detrimento dos saberes e práticas culturais locais dos povos tradicionais, integrados às suas identidades comunitárias (ARAÚJO, 2011).

Em suma, as políticas tradicionais partem de uma lógica perversa que nega a importância da diversidade cultural e os saberes tradicionais, hipervalorizando o saber científico e os interesses de mercado que reforçam tanto a dissociação da sociobiodiversidade quanto os modelos econômicos capitalistas que se baseiam na exploração dos seus recursos. Em contrapartida, as respostas da sociedade a esses esquemas tradicionais revelam estratégias contra-hegemônicas, sejam elas derivadas de aspectos sociais, culturais, políticos ou econômicos, 
que buscam suplantar o direito e a prática política dos Estados na proteção da sociobiodiversidade.

\section{A COOPERAÇÃO DESCENTRALIZADA E A AÇÃO COLETIVA NA PROTEÇÃO DA SOCIOBIODIVERSIDADE}

A "pedra angular" da sociobiodiversidade ${ }^{3}$ reside justamente na relação mantida entre o ser humano e o ambiente em que vive. Logo, a sua preservação depende essencialmente do aspecto cultural das relações das pessoas com a natureza e do uso ou exploração dos recursos naturais. Ou seja, há uma implicação entre modelos culturais, biodiversidade e diversidade cultural, de tal forma que a diminuição ou impacto provocado em relação a um desses aspectos acarreta repercussões em outro. Portanto, o balanceamento entre os sistemas é fundamental para o equilíbrio e preservação da sociobiodiversidade, possibilitando formas sustentáveis de desenvolvimento econômico e social (ARAÚJO, 2011).

Nesse sentido, a ideia de desenvolvimento sustentável vai ao encontro dos modelos predominantes de crescimento econômico e que geralmente estruturam as ações dos governos e atores privados do mercado, baseados na exploração predatória dos recursos naturais. Nesse ínterim, pensar sobre desenvolvimento sustentável não é apenas pensar sobre alternativas para solucionar os problemas ambientais, mas principalmente repensar criticamente os modelos sociais, políticos e culturais nos quais essas alternativas são colocadas em prática (CAMARGO, 2005).

Partindo da ideia de sustentabilidade, busca-se integrar a ideia de desenvolvimento aos interesses sociais e econômicos sem desconsiderar, para tanto, os limites e possibilidades dos recursos naturais. Ou seja, o objetivo é promover a harmonia entre os interesses dos seres humanos e da natureza, uma vez que nem o desenvolvimento é possível com a deterioração dos recursos naturais, nem a natureza pode ser protegida caso o desenvolvimento não leve em consideração os impactos da degradação ambiental (CAMARGO, 2005).

Ocorre que os modelos econômicos, políticos e sociais, que são experimentados hoje na sociedade internacional, ainda privilegiam os interesses de apenas alguns atores e setores da sociedade, principalmente dos Estados e dos agentes de mercado. Nesse passo, não raro as decisões políticas e econômicas contrariam os interesses sociais e violam direitos, provocando opressão e degradação de culturas e do meio ambiente ao redor do mundo (SHIVA, 2001).

Nesse cenário, o setor privado tem adquirido cada vez mais força, enquanto os Estados vêm perdendo não só o seu protagonismo, mas igualmente a sua força política e credibilidade. Como forma de revalidar sua importância, por vezes os Estados se aliam a interesses escusos e parciais de outros atores influentes no contexto internacional. Assim, não só há um reforço do déficit democrático 
sobre os interesses sociais e culturais que deveriam ser preservados, mas também o estímulo a movimentos contra-hegemônicos (ARNAUD, 1999).

Além disso, partindo-se da lógica herdada da modernidade, as ideias de Estado, política e Direito tornaram-se praticamente indissociáveis. Ou seja, é muito difícil ou quase impossível pensar em política "fora do Estado" ou em Direito sem que seja um produto da política do Estado (ARNAUD, 1999). Segundo essa métrica, passou-se a pensar na força do Direito como um aspecto da força e do poder político do Estado:

Essa é uma realidade que se verifica em toda América Latina, na qual as comunidades que tendem a uma práxis em sentido coletivo veem-se espremidos pelo avanço do um sistema cuja lógica é a do mercado internacional, que para o atendimento de seus interesses subverte as formas locais de produção. Nesse momento, os direitos consuetudinariamente criados por essas comunidades e que embasam suas relações sociais, são simplesmente suprimidos, dando lugar ao direito positivado. (ARAÚJO, 2011, p. 350)

Todavia, a autonomia dos Estados tem sido bastante comprometida pela interdependência que se desenvolve no seio de uma economia globalizada. E considerando o déficit das ações estatais na gestão de recursos globais e locais comuns, o direito estatal corre o risco de ser concretamente suplantado por outros tipos de regulação global em decorrência do aparecimento de ordens espontâneas em que escapam à regulação estatal, bem como pela ameaça que pesa sobre o equilíbrio internacional.

É justamente quando se trata do equilíbrio internacional que podemos observar com mais facilidade como o Estado se deixa suplantar na sua prerrogativa de proferir o direito. Diante disso, cada vez mais se vê dissociada do Estado a possibilidade de ação política e de produção do direito. Ou seja, a democracia deixou de ser um assunto apenas dos Estados, podendo se falar, hoje, num movimento de democratização global iniciado desde as raízes dos grupos e movimentos sociais, que criam uma definição alternativa da democracia, motivada pela necessidade de sua ampliação, para incluir práticas sociais e culturais que não sejam somente as do Estado.

Nesse contexto se inserem as discussões sobre governança global, ou seja, sobre a possibilidade de governança sem que haja um governo, e menos ainda um governo exclusivamente de Estado. Trata-se de um fenômeno amplo que envolve uma multiplicidade de atores, sejam eles estatais ou não, que se associam entre si na administração de bens e questões globais (CARRION; LORENZETTI, 2012).

A governança global (Global Challenges Foundation, 2017; D. Held, 1995) pode ser entendida como a estratégia por meio da qual diferentes atores enfrentam interesses conflitantes por meio da ação coletiva, envolvendo 
diversos canais de ação, como as instituições internacionais, a sociedade civil, as organizações não governamentais (HIGGOT, 2005). Nesse sentido o objetivo da governança global, grosso modo, é fornecer bens públicos globais (global public goods), particularmente a paz e a segurança, justiça e sistemas de mediação para conflitos, mercados em funcionamento e padrões unificados para o comércio e a indústria. Um dos bens públicos considerado crucial é o gerenciamento de riscos catastróficos - implementando mecanismos apropriados para reduzir ao máximo a probabilidade e o impacto de qualquer evento que possa causar a morte de milhões de pessoas em todo o planeta ou danos de magnitude equivalente (Global Challenges Foundation, 2017; D. Held, 1995). Permite-se pensar, assim, na hipótese de uma governança multinível, que envolva diversos níveis territoriais e ações políticas em rede que não estão restritas aos limites das esferas públicas tradicionais.

Essa ideia da governança multinível propõe uma administração horizontal e não vertical de bens, justamente por levar em consideração a complexificação das relações socioeconômicas e culturais na sociedade global, assim como a interdependência entre os grupos e pessoas, principalmente entre atores estatais e não estatais (YAHN FILHO, 2011).

No contexto da governança, o conceito de cooperação descentralizada que porventura nasceu no Sul precisamente em 1989, com a Convenção de Lomé IV (Togo), surge como um instrumento para pensar práticas em rede a partir do questionamento sobre os instrumentos tradicionais de cooperação tradicional e dos interesses que esses acordos preservam (DESSOTTI, 2009). Basicamente, esse modelo de cooperação se caracteriza por ser um conjunto de iniciativas de cooperação para o desenvolvimento que procura estimular as capacidades de atores da sociedade civil, como os movimentos sociais, a pensarem e executarem ações políticas com o objetivo de administrar bens em comum (ROMERO, 2006).

A ideia de descentralização parte desde a camada mais baixa da sociedade, atingindo políticas de ação e efeito micro e não macro, além de compreender a atuação de "novos atores" da sociedade civil, como instituições de pesquisa, ONGs, movimentos sociais, empresas etc. Estes "novos atores" surgem a partir da dinâmica cada vez mais complexa das relações internacionais, alterando a lógica da importância política dos Estados e das ações tradicionais de governo. Umas das mais pertinentes definições de cooperação descentralizada encontram-se proferida por Maria Afonso e Ana Fernandes (2005) ao anotar que

“(...) a cooperação descentralizada consiste na cooperação realizada por entidades sub-estatais (municípios, regiões, instituições de ensino, entre outras), isto é, entidades que não fazem parte da Administração Central do Estado. Este tipo de cooperação constitui uma nova abordagem da cooperação, que tem como características principais as seguintes: descentralização das iniciativas e da relação com os países em desenvolvimento; inclusão de uma 
grande variedade de novos actores da sociedade civil e, por fim, uma participação activa dos beneficiários, dos países em vias de desenvolvimento (...)"

Assim, a cooperação deixa de ser um instrumento político exclusivo dos governos, refletindo a diversificação dos centros de poder cujas práticas não são estruturadas a partir do Estado. Por isso mesmo ela é mais inclusiva, permitindo que os atores locais, como os movimentos sociais, tornem-se sujeitos cada vez mais ativos e combativos ao adotarem práticas políticas que evidenciam a ausência ou deficiência da ação do Estado (VILLA, 2001). Segundo Luiz Ernani Bonesso de Araújo:

No momento em que há uma gradativa recuperação das liberdades públicas, surgem na sociedade civil manifestações de diferentes grupos sociais, que vão desde as minorias étnicas, passando pelas discussões de gênero, organização de associações de bairros, comunidades rurais, e de forma acentuada, o movimento ambientalista. Nessa diversidade de manifestações sociais e culturais, há uma convergência para um ponto comum, reafirmamse os direitos notadamente individuais, ao mesmo tempo em que passa a admitir os direitos coletivos. (ARAÚJO, 2011, p. 351-352)

Isso ocorre até mesmo em razão do fato de que a política eficaz somente vai ocorrer a nível micro e não macro. Consequentemente, são os atores locais que conseguem definir quais são as precariedades enfrentadas no dia a dia, expressando melhor a necessidade de se buscar ações específicas que promovam a solução dos problemas mais assertivamente, principalmente no que diz respeito a relação com o meio ambiente.

A partir da ideia de luta social, governança global e da cooperação descentralizada dos movimentos sociais, a definição da justiça ambiental enquanto categoria acaba sendo ampliada, abarcando diversos conjuntos de princípios e práticas mais democráticos e compatíveis com a realidade social. Segundo Henri Acselrad, esses princípios e práticas:

a - Asseguram que nenhum grupo social, seja ele étnico, racial ou de classe, suporte uma parcela desproporcional das consequências ambientais negativas de operações econômicas, de decisões de políticas e de programas federais, estaduais, locais, assim como da ausência ou omissão de tais políticas;

b - Asseguram acesso justo e equitativo, direto e indireto, aos recursos ambientais do país;

c - Asseguram amplo acesso às informações relevantes sobre o uso dos recursos ambientais e a destinação de rejeitos e localização de fontes de riscos ambientais, bem como processos democráticos e participativos na definição de políticas, planos, programas e projetos que lhes dizem respeito; 
d - Favorecem a constituição de sujeitos coletivos de direitos, movimentos sociais e organizações populares para serem protagonistas na construção de modelos alternativos de desenvolvimento, que assegurem a democratização do acesso aos recursos ambientais e a sustentabilidade do seu uso. (ACSELRAD, 2004, p. 13-20)

Essa ideia de justiça ambiental, portanto, parte de uma criatividade estratégica de movimentos e grupos sociais, como a ideia de cooperação internacional descentralizada de certos bens compartilhados que os Estados falham ou não tem interesse efetivo em proteger. Essas práticas provocam uma reconfiguração das lutas ambientais e podem chegar até mesmo a produzir mudanças no aparelho estatal (ACSELRAD, 2010, p. 111).

Exemplo disso é o manifesto lançado pelo Greenpeace após as eleições presidenciais de 2018, diante da preocupação com as políticas de (des)proteção ambiental fomentadas pelo então candidato eleito e atual presidente do Brasil. Esse manifesto, chamado "Todos juntos em defesa do meio ambiente", foi apresentado por mais de cinquenta redes de movimentos e organizações sociais não governamentais nacionais e internacionais, contemplando princípios e práticas de proteção e luta ambiental. Segundo consta no documento:

\begin{abstract}
Defender o fim do ativismo - inclusive do ambiental - representa afronta à Constituição Federal e à democracia, que asseguram livre direito de expressão, de organização, manifestação e mobilização social na defesa de direitos. Isso se torna ainda mais grave em função da posição ocupada pelo Brasil de recordista mundial em assassinatos de defensores do meio ambiente. (...) Diante da gravidade deste cenário à área socioambiental, as organizações signatárias vêm alertar à sociedade brasileira e à comunidade global sobre os riscos concretos e irreversíveis a que estão expostas. (GREENPEACE BRASIL, 2018)
\end{abstract}

Embora ainda não seja possível dizer que esses movimentos e práticas encontraram soluções em escala global para a maioria dos problemas ambientais, ainda assim a mobilização desses movimentos da sociedade civil certamente resulta em consequências certamente positivas. Isso leva ao crescimento e fomento da luta ambiental pela proteção da sociobiodiversidade, solidificando as ações desses movimentos e garantindo o retorno da sociedade civil ao cuidado e exercício direto de práticas políticas de cuidado do que não é do Estado, mas sim de todos.

\title{
CONCLUSÃO
}

Avaliando o contexto político e socioeconômico ao longo das últimas décadas, não é difícil concluir que os Estados e as instituições internacionais têm 
falhado sistematicamente na busca de soluções para inúmeros problemas globais. Pior que isso, em relação a muitos deles os Estados e as instituições acabam se revelando os seus principais agentes causadores, ao invés de atuarem na contenção e na busca de soluções adequadas.

As questões ambientais são um nítido exemplo de como os Estados, enquanto atores tradicionais das relações internacionais e produtores centrais do Direito interno e internacional, ainda falham na adoção de medidas que sejam adequadas e eficazes à preservação da sociobiodiversidade. Mais a vaga de revisionismo e protecionismo que definido as políticas externas de várias potencias não tem ajudado alcançar o tal desejado consenso em relações a desafios e problemas globais. Basta referir a retirada do presidente estadunidense D. Trump do Tratado de Paris.

Nesse sentido, considerando que os Estados não se tornaram apenas em reféns, mas também em reprodutores da lógica capitalista, os problemas ambientais acabam se estendendo sistemicamente ao longo de todo o planeta, ao passo em que as normas de direito internacional, incluindo-se os acordos de cooperação para a proteção ambiental, transformam-se em mera retórica à mercê dos interesses econômicos.

Consequentemente, considerando que a lógica e a importância central da ação política são definidas pelo fator da presença, onde falha o Estado surgem espaços para a ação coletiva, provocando um retorno da sociedade civil na administração de bens comuns negligenciados pelas políticas hegemônicas estatais. Isso por si só permite se pensar em estratégias mais flexíveis e abertas à participação de novos atores sociais, pois a fuga do esquema político dominado pelos Estados favorece o caráter democrático desses novos canais de ação coletiva.

Essas novas práticas se inserem na ideia de governança global, levando em consideração a complexidade e dinamicidade das relações sociais, econômicas e culturais atuais, assim como a inter-relação entre o destino de sujeitos e grupos sociais, e entre atores tradicionais e não tradicionais das relações internacionais. Um forte exemplo dessas práticas é a cooperação internacional descentralizada, por meio da qual as pessoas, organizações não governamentais, movimentos sociais etc. exercem governança sobre bens compartilhados sem que haja a necessária inserção da política ou governo de Estado.

No caso do meio ambiente, essas práticas reforçam o caráter democrático e mais responsivo das medidas relacionadas à proteção da sociobiodiversidade, respeitando os saberes e práticas culturais locais, e invertendo o paradigma do desenvolvimento de uma perspectiva macropolítica, que ascenda aos interesses globalizantes do mercado, para uma perspectiva micropolítica. Ou seja, pensar sobre uma cooperação internacional de atores preocupados de fato com as questões ambientais, sem que haja a intersecção de interesses contraditórios, como os econômicos, não apenas corresponde a uma prática contra-hegemônica, mas possibilita que os bens em comum / global public goods sejam geridos a partir das próprias práticas culturais inclusivas dos movimentos sociais. 


\section{NOTAS}

1 Apesar os dois conceitos sejam usados como sinônimos, há autores que separam os conceitos. Usamos aqui os dois conceitos mas cada um no seu sentido, enquanto a globalização refere à maior integração nos níveis políticos, econômicos e sociais, a mundialização diz respeito a cultura no seu globo.

2 Há que realçar que o conceito desenvolvimento essencialmente da ciência económica antes de tornar interdisciplinar, advém desde Adam Smith que tentou explicar as causas da riqueza das nações, mas que ganhou folgo com a revolução industrial na Europa. A referência ao bem-estar e ao progresso apenas foi difundida conceptualmente após segunda guerra mundial. Sobre a história do polémico conceito veja-se Rogério Roque Amaro, "Desenvolvimento - um conceito ultrapassado ou em renovação? Da teoria à prática e da prática à teoria", Cadernos de Estudos Africanos [En ligne], 4 | 2003, disponível desde 25 julho 2014, consultado em 19 dezembro 2019. URL: http://journals. openedition.org/cea/1573; DOI: 10.4000/cea.1573

3 Há que sublinhar aqui a importância do conceito da sociobiodiversidade formulado por Luiz Ernani Bonesso de Araújo e que busca analisar e apreender a relação intrínseca e secular entre sociedade, cultura e biodiversidade. Veja-se (Araújo 2011)

\section{REFERÊNCIAS}

ACSELRAD, H. Justiça ambiental: ação coletiva e estratégias argumentativas. In: ACSELRAD, Henri (Org.). Justiça ambiental e cidadania. Rio de Janeiro: Relume Dumará, 2004.

. Ambientalização das lutas sociais - o caso do movimento por justiça ambiental. Estudos Avançados, São Paulo, v. 24, n. 68, p. 103-119, 2010.

AFONSO, M. e FERNANDES, A, “abCD Introdução à Cooperação para o Desenvolvimento", Instituto Marquês de Valle Flôr e Oikos - Cooperação e Desenvolvimento; Lisboa, 2005.

AMARO, ROGERIO ROQUE, «Desenvolvimento - um conceito ultrapassado ou em renovação? Da teoria à prática e da prática à teoria», Cadernos de Estudos Africanos [En ligne], 4 | 2003, disponível desde 25 julho 2014, consultado em 19 dezembro 2019. URL: http://journals.openedition.org/cea/1573; DOI: 10.4000/cea.1573

ARAÚJO, L. E. B. Repensando o Direito da Biodiversidade a Partir de um Paradigma Tropical. In: Ana Mirka Seitz; Fernando Estenssoro Saavedra; Gilmar Antonio Bedin; Jerônimo Siqueira Tybusch; Luiz Ernani Bonesso de Araújo; Vinícius Garcia Vieira. (Org.). América Latina e Caribe na Encruzilhada Ambiental. 1 ed. Ijuí, RS: Unijuí, 2011, v. 1, p. 339-354.

ARNAUD, André-Jean. O direito entre a modernidade e globalização: lições de filosofia do direito e do Estado. Rio de Janeiro: Renovar, 1999.

CAMARGO, A. L. de B. Desenvolvimento sustentável: dimensões e desafios. Campinas: Papirus, 2005. 
CERQUEIRA, C. F. M. Da interdependência ambiental à cooperação multilateral: um novo paradigma de relações internacionais em delineamento. 1994. 120 f. Dissertação (Mestrado em Relações Internacionais) - Instituto de Relações Internacionais, Universidade de Brasília, Brasília, 1994.

DESSOTTI, F. R. Cooperação Descentralizada: Uma Inovação nas Políticas Públicas de Desenvolvimento Local. In: $5^{\circ}$ Congrès de I'Institut Franco-Brésilien d'Administration dês Entreprises, 18 e 19 de maio 2009. França.

ESTADÃO. Bolsonaro diz que aceita ajuda do G7 se Macron se desculpar por "insultos". 27 de agosto de 2019. Disponível em: <https://exame.abril.com.br/brasil/bolsonaro-dizque-aceita-ajuda-se-macron-se-desculpar-por-insultos/>

Global Challenges Foundation, Global governance models in history, 2017 Disponível em https://globalchallenges.org/global-governance/

GREENPEACE BRASIL. Todos juntos em defesa do meio ambiente. 19 de outubro de 2018. Disponível em: <https://www.greenpeace.org/brasil/blog/todos-juntos-em-defesado-meio-ambiente/>

HELD, D. Democracy and the global order: from the modern state to cosmopolitan governance. Open University, 1995.

HIRST, Paul; THOMPSON, Grahame. Globalização em questão. Rio de Janeiro: Vozes, 1998

LE PRESTRE, P. Ecopolítica internacional. São Paulo: Editora SENAC, 2000.

LORENZETTI, J. V.; CARRION, R. M. Governança ambiental global: atores e cenários. Cadernos EBAPE.BR (FGV), v. X, p. 721-735, 2012.

ORTIZ, Renato. Mundialização e cultura. São Paulo: Brasiliense, 1994.

RIBEIRO, W. C. Cooperação internacional. In: Almanaque Brasil Socioambiental, Instituto Socioambiental, São Paulo, 2007.

ROMERO, M. H. La cooperación descentralizada local. Aportes para la construcción de un marco de referencia conceptual en el espacio de las relaciones Unión EuropeaAmérica Latina. Anuario del Observatorio de la Cooperación Descentralizada. 65 Montevideo: Consorcio Diputació de Barcelona-Intendencia Municipal de Montevideo, 2006.

SÁNCHEZ, E. R. Cooperación y Desarrollo: Nueve Preguntas sobre el Tema. Amycos, 2002.

SHIVA, V. Biopirataria: A pilhagem da natureza e do conhecimento. Rio de Janeiro: Vozes, 2001.

TOURME-JOUANNET, E. What is a Fair International Society? International Law Between Development and Recognition. Oxford: Hart Publishing, 2013. 
ULLRICH, D.; CARRION, R. S. M. A Atuação do Brasil na Cooperação Internacional para o Desenvolvimento: o desafio do compartilhamento de saberes. Desenvolvimento em Questão, v. 20, p. 4-27, 2012.

VILLA, R. D. Atores não-estatais e meio ambiente nas relações internacionais:

Greenpeace e a Antártica. Desenvolvimento e Meio Ambiente, n. 4, p. 45-57, jul./dez. 2001.

YAHN FILHO, A. G. . Mercocidades e governança multinível no processo de integração regional sul-americano. In: $3^{\circ}$ Encontro Nacional da ABRI: Governança global e novos atores, São Paulo. $3^{\circ}$ Encontro Nacional da ABRI: Governança global e novos atores, v. 1, 2011.

Submetido: $30 / 01 / 2020$

Aceito: 05/02/2020 


\title{
A COOPERAÇÃO INTERNACIONAL DESCENTRALIZADA COMO ESTRATÉGIA PARA A PROTEÇÃO DA SOCIOBIODIVERSIDADE
}

\begin{abstract}
Resumo
O presente trabalho tem por finalidade investigar o papel dos novos atores das relações internacionais, como os movimentos sociais e organizações não governamentais, na construção de redes de cooperação descentralizada para a proteção da sociobiodiversidade. Para tanto, utilizou-se o método de abordagem dialético, associado ao método de procedimento funcionalista e das técnicas de pesquisa bibliográfica. Concluiu-se que os novos atores das relações internacionais vêm exercendo papéis cada vez mais acentuados e decisivos, desafiando o papel dos Estados e adotando práticas mais eficazes de proteção e conscientização ambiental. Além disso, essas práticas políticas sugerem novos enfoques críticos para o Direito Internacional, incitando outras formas de pensar sobre o seu papel na proteção do meio ambiente. Ademais, a cooperação internacional descentralizada desses atores constitui uma potente ferramenta de governança global, pautada no desenvolvimento sustentável e na garantia de condições mais dignas para as futuras gerações.
\end{abstract}

Palavras-chave: Cooperação descentralizada; desenvolvimento sustentável; governança global. 


\title{
DECENTRALIZED INTERNATIONAL COOPERATION AS A STRATEGY FOR THE PROTECTION OF SOCIOBIODIVERSITY
}

\begin{abstract}
This paper aims to investigate the role of new actors in international relations, such as social movements and non-governmental organizations, in the construction of decentralized cooperation networks for the protection of socio-biodiversity. For this, we used the dialectical approach method, associated with the functionalist procedure method and bibliographic research techniques. It was concluded that the new actors in international relations have been playing increasingly pronounced and decisive roles, challenging the role of states and adopting more effective practices of environmental protection and awareness. In addition, these political practices suggest new critical approaches to international law, prompting other ways of thinking about their role in protecting the environment. Moreover, the decentralized international cooperation of these actors is a powerful tool for global governance, based on sustainable development and guaranteeing more decent conditions for future generations.
\end{abstract}

Keywords: Decentralized cooperation; sustainable development; global governance. 